\section{Learning Outcomes for Contemporary and Future Practice: Are We There Yet?}

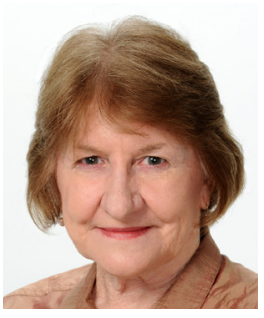

Margaret McMillan

School of Nursing and Midwifery, University of Newcastle, Australia

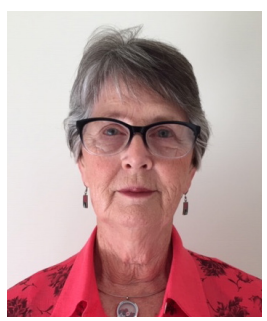

\section{Penelope Little}

School of Nursing and Midwifery, University of Newcastle, Australia

Changing paradigms in education and practice are generally, but not always, evolutionary in nature - ideas are developed and expanded upon within preferred curriculum designs. While practice-based curriculum development is influenced by ideology and culture, principles around maintaining close alignment between education and practice remain. In learner-centred learning for the professions its also all about keeping the focus on the learning outcomes for students. However, any choices in learning activities are strongly influenced by patterns of disease, professional standards, policy ie, around scope of practice, regulations for the various professions, changing population demographics, advances in health service and educational technology and often the personal styles and preferences of academics.

One revolutionary development from the 1980s was the emergence of e-Learning. There is a clear continuing trend towards more self-direction in learning (SDL), especially since the uptake of technology-supported access to learning activities beyond the traditional classrooms. This greater autonomy in learning became more evident from the time of the introduction of computer-assisted learning in the 1980s-90s resulting in a change of pattern in how students accessed resources: One could see students' patterns in accessing resources which became more accessible as e-resources evolved. As the movement towards greater online and blended modes of program implementation grew, it was evident that rich resources for stimulus material was available; students were less reliant on teacher-centred resources. However, it was also clear to curriculum reviewers that sometimes there was a lack of translation of elements of curriculum philosophy and methodology into the learner-managed processes; appropriate scaffolding and directions for students were often limited or even missing.

It is essential for students to take responsibility for their own learning. By modelling collaborative and group-based activities, similar concepts can be transferred to facilitation of appropriately co-ordinated plans for self-care by patients/clients. However, learning activities must be structured to facilitate not only students' ability for SDL but other learning outcomes such as greater depth in thinking, an orientation to ethical, lawful and professional behaviours, skill in determin-

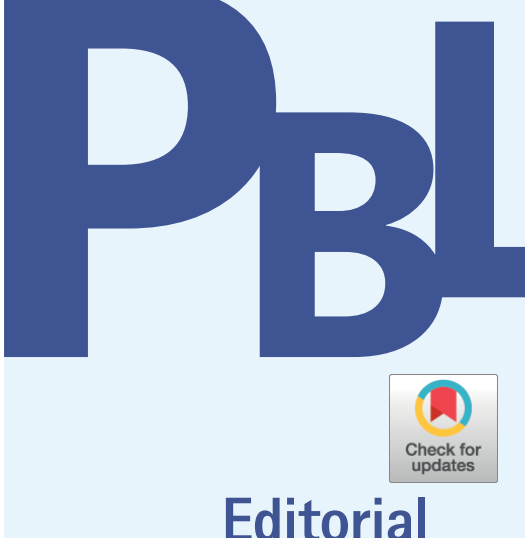

pISSN 2288-8675 · elSSN 2508-9145

J Probl Based Learn 2019;6(2):45-46 https://doi.org/10.24313/jpbl.2018.00122

Received: September 30, 2019

Accepted: October 16, 2019

Corresponding author:

Margaret McMillan

School of Nursing and Midwifery, University of Newcastle, 66 Rickard

Street, Bateau Bay, NSW 2261, Australia

Tel: +61-408-431269

E-mail: margaret.mcmillan@ newcastle.edu.au
(C) Copyright 2019 International Society for Problem-Based Learning

(c) This is an Open Access article distributed under the terms of the Creative Commons Attribution Non-Commercial License (http://creativecommons.org/licenses/ by-nc/4.0/) which permits unrestricted non-commercial use, distribution, and reproduction in any medium, provided the original work is properly cited. 
ing the worthiness of evidence, heightened awareness of the rights and needs of clientele.

Becoming a health professional occurs through being able to think and act like

- a nurse or a physiotherapist, an occupational therapist, a medical emergency care worker or a doctor. How professionals conceptualize practice shapes what they learn from practice: Students should be encouraged to observe practice and explore alternatives when tensions arise between the ideal and actual practice. It is the skill in enquiry processes (the thinking about) that enables students to develop meaningful knowledge about their professional practice.

From our experience, most curriculum documents reflect a commitment to

1. Enquiry processes involving critical thinking and

2. Reflection on learning

However, closer scrutiny of implementation shows that these two essential elements of programs require ongoing development as each new student cohort begins a journey towards becoming confident and competent professionals.

Curriculum developers often ask 'what options do we have for curriculum renewal that achieves greater student engagement?' 'How do I manage an online classroom?' Irrespective of modifications to stimulus material, there is a constant need to ensure that health professional education reflects flexibility for teacher's creativity in causing students to examine novel and messy situations that focus on

1. encouraging students to view situations from a range of perspectives

2. the learners' needs through the use of authentic stimulus material, allowing them to embrace the concepts and activities essential to practice

3. challenging students to question and justify the practice and challenge their values and beliefs

4. emphasising the ability to think about their discipline

5. focussing on performing actions to manage situations
6. challenging students to continue with lifelong learning and professional development based on evidence-based practice.

In response to the question 'Are we there yet?' the answer is embedded in the integrity of one's interrogation of the curriculum blueprint. Good governance of curriculum will ensure consistent use of an acceptable philosophy. Ongoing interrogation of implementation efforts will lead to appropriate refreshment and/ or renewal of stimulus material that reflects contemporary clinical practice.

So what of the future? Drivers of curriculum development include the need to consider the notion that the health and higher education workforces and workplaces are changing dramatically. These changes are also influenced by larger student enrolments because of more accessible mass education and advances in technology. In the academic workplace there is a need to demonstrate greater clarity around the complementary but different roles of the academics and clinicians, technicians and administrators; they are inextricably entwined in the contemporary environment but academic judgment is the domain of the educator. A vast range of potential stimulus material is readily available given advances in technology, but those involved in governance processes have a responsibility to encourage users to determine the relevance and worthiness of resources. While students are demonstrating greater self direction in learning activities, educators need to be vigilant about the strength of enquiry and reflection processes and outcomes.

Professional development of academics needs to include an understanding of their practice if their students are to achieve meaningful learning, especially when technology is involved in the expectation of enhancing learning. This should include some appreciation of theory that underpins their assumptions about learning and teaching. Greater awareness of theoretical underpinnings of learning processes can provide answers to questions such as "What type of learner does society need for the future workplace and society more generally?" 